\title{
Fewer Cancer Cases in 4 Countries of the WHO European Region in 2018 through Increased Alcohol Excise Taxation: A Modelling Study
}

\author{
Pol Rovira ${ }^{a}$ Carolin Kilian $^{b}$ Maria Neufeld ${ }^{b, c, d}$ Harriet Rumgay ${ }^{e}$ \\ Isabelle Soerjomataram $^{e}$ Carina Ferreira-Borges ${ }^{c}$ Kevin D. Shield ${ }^{d, f}$ \\ Bundit Sornpaisarn ${ }^{d, f, g}$ Jürgen Rehm ${ }^{a, b, d, f, h, i, j}$
}

\begin{abstract}
aProgram on Substance Abuse, Public Health Agency of Catalonia, Barcelona, Spain; b Institute of Clinical Psychology and Psychotherapy \& Center for Clinical Epidemiology and Longitudinal Studies, Technische Universität Dresden, Dresden, Germany; 'WHO European Office for Prevention and Control of Noncommunicable Diseases, Moscow, Russian Federation; ${ }^{~ I n s t i t u t e ~ f o r ~ M e n t a l ~ H e a l t h ~ P o l i c y ~ R e s e a r c h, ~ C e n t r e ~ f o r ~ A d d i c t i o n ~ a n d ~ M e n t a l ~ H e a l t h ~(C A M H), ~}$ Toronto, ON, Canada; eSection of Cancer Surveillance, International Agency for Cancer Research, Lyon, France; fDalla Lana School of Public Health, University of Toronto, Toronto, ON, Canada; '9Faculty of Public Health, Mahidol University, Bangkok, Thailand; ${ }^{\mathrm{h} C a m p b e l l}$ Family Mental Health Research Institute, CAMH, Toronto, ON, Canada; 'Department of Psychiatry, University of Toronto, Toronto, ON, Canada; 'Department of International Health Projects, Institute for Leadership and Health Management, I.M. Sechenov First Moscow State Medical University, Moscow, Russian Federation
\end{abstract}

\section{Keywords}

Taxation $\cdot$ Cancer $\cdot$ Incidence $\cdot$ Alcohol $\cdot$ Europe

\begin{abstract}
Introduction: Prevention of cancer has been identified as a major public health priority for Europe, and alcohol is a leading risk factor for various types of cancer. This contribution estimates the number of cancer cases that could have potentially been averted in 2018 in 4 European countries if an increase in alcohol excise taxation had been applied. Methods: Current country and beverage-specific excise taxation of 4 member states of the WHO European Region (Germany, Italy, Kazakhstan, and Sweden) was used as a baseline, and the potential impacts of increases of 20,50 , and $100 \%$ to current excise duties were modelled. A sensitivity analysis was performed, replacing the current tax rates in the 4 countries by those levied in Finland. The resulting increase in tax was assumed to be fully incorporated into the consumer price, and
\end{abstract}

beverage-specific price elasticities of demand were obtained from meta-analyses, assuming less elasticity for heavy drinkers. Model estimates were applied to cancer incidence rates for the year 2018. Results: In the 4 countries, $>35,000$ cancer cases in 2018 were caused by alcohol consumption, with the highest rate of alcohol-attributable cancers recorded in Germany and the lowest in Sweden. An increase in excise duties on alcohol would have significantly reduced these numbers, with between 3 and $7 \%$ of all alcohol-attributable cancer cases being averted if taxation had been increased by $100 \%$. If the 4 countries were to adopt an excise taxation level equivalent to the one currently imposed in Finland, an even higher proportion of alcohol-attributable cancers could be avoided, with Germany alone experiencing 1,600 fewer cancer cases in 1 year. Discussion/Conclusion: Increasing excise duties can markedly reduce cancer incidence in European countries.

(C) 2020 The Author(s) Published by S. Karger AG, Basel karger@karger.com www.karger.com/ear

Karger $\frac{1}{\%}$

GOPEN ACCESS
(C) 2020 The Author(s)

Published by S. Karger AG, Basel

This is an Open Access article licensed under the Creative Commons Attribution-NonCommercial-4.0 International License (CC BY-NC) (http://www.karger.com/Services/OpenAccessLicense), applicable to the online version of the article only. Usage and distribution for commercial purposes requires written permission.
Jürgen Rehm

CAMH

33 Ursula Franklin Street

Toronto, ON M5S 2S1 (Canada)

jtrehm@gmail.com 


\section{Introduction}

Reducing the health burden caused by cancer is a top European health priority. Indeed, the European Union (EU) issued a European plan to fight cancer [1], which stressed prevention as one of its 4 pillars. Similarly, the World Health Organization (WHO) Regional Office for Europe, whose member states also include Eastern European countries outside of the EU and Central Asian countries, has established the prevention and control of noncommunicable diseases, especially cancer, as a public health priority $[2,3]$. Further, numerous key organizations of the European Public Health Alliance issued a joint statement in 2020 placing prevention at the heart of Europe's Beating Cancer Plan [4].

Alcohol use is one of the major causes of cancer $[5,6]$, particularly in Europe, which has the highest level of alcohol consumption globally [7] (for the alcohol-attributable cancer burden, see $[8,9])$. In a comprehensive study comparing the impact of different risk factors on the incidence of cancer, alcohol was found to be the second leading cause of cancer in France after tobacco smoking [10].

Effective and cost-effective alcohol control policies can decrease the burden of disease caused by alcohol use $[11,12]$. Increasing the price of alcoholic beverages by increasing alcohol-specific taxation is the most effective such policy in terms of costs involved and the time required for implementation. Accordingly, this study estimated the effect of increasing excise taxation by 20,50 , and $100 \%$ on cancer incidence in 4 member states of the WHO European Region: Germany, Italy, Kazakhstan, and Sweden.

\section{Materials and Methods}

\section{Selection of Countries}

Four countries were selected to assess the effects of increasing excise taxes on cancer incidence based on their differing levels and patterns of alcohol consumption and alcohol policies. The 4 countries include Germany, Italy, Kazakhstan, and Sweden.

Germany, a high-income country, where beer is the most consumed beverage [13] was selected since it has one of the highest levels of alcohol use globally [7] (level of alcohol use is usually expressed in adult alcohol consumption per capita - APC - in litres pure alcohol [14]) and liberal alcohol control policies, including low taxation rates [15], resulting in high affordability of alcoholic beverages [16].

Italy, another high-income country, where wine is the most frequently consumed beverage [13], was selected due to its relatively liberal alcohol control policies similar to Germany's [15] but in combination with a much lower APC compared to Germany.
The current lower levels of alcohol use resulted after several decades of continued decrease, related to industrialization, globalization, and social measures of control, which, among other causes, have reduced the tradition of consuming alcohol with both lunch and dinner on the same day [17].

Kazakhstan, an upper middle-income country, was selected due to its large Muslim population (about 70\% Muslims [18]) and therefore its high prevalence of abstainers [7]. However, similar to Eastern European countries, the volume of alcohol consumed by drinkers is relatively high, and the preferred beverage is spirits [13]. Furthermore, within the last decade, several of the WHO "best buy" policies for alcohol control have been implemented in Kazakhstan, resulting in relatively high rates of taxation (see below and [15]).

Sweden, a high-income country, was selected due to its relatively low APC (lower than the average EU country) and due to a switch in patterns of drinking in the last decades from spirits to wine as the preferred beverage [13]. Sweden traditionally has restrictive alcohol policies [15]. An overview of alcohol indicators for the 4 selected countries is provided in online supplementary Appendix Table A1; for all online suppl. material, see www.karger. com/doi/10.1159/000511899.

\section{Building Different Taxation Scenarios}

Since the main objective of this study is to see how many cancer cases could have been averted by increasing excise taxes on alcohol, the first step was to obtain information on the current taxation policies and the mean price per litre of each alcohol beverage type, to determine the percentage of the price represented by tax. For the 3 countries that are part of the EU, the current duties for alcohol are available at [19] and the data on the mean price have been obtained from the Statista webpage [20]. For Kazakhstan, we relied on government data, from the national taxation plan, for the level of excise duties [21] and for a number of sources for current prices (see online suppl. Appendix). An overview of all data and procedures can be found in the online supplementary Appendix.

Alcoholic beverages were categorized into 3 major groups: beer, wine, and spirits. In order to evaluate the mean proportion of the alcohol tax for each type of alcohol beverage, the mean percentage of pure alcohol for each beverage was assumed to be 5, 12.5 , and $40 \%$ for beer, wine, and spirits, respectively (same assumptions as in [13]). Alcohol excise taxation statistics, by country and beverage type, are outlined in Table 1.

In this study, 3 different scenarios were simulated to determine the effects after excise taxes for each of 3 main alcoholic beverage types are increased by 20,50 , and $100 \%$ (for similar analyses, see $[11,12])$. To apply an increase in excise duties to wine for Germany and Italy, where there is currently no such taxation (see Table 1), the same tax percentage as for beer was assumed (i.e., a cheap taxation rate was applied).

Producers were assumed to pass the cost of the tax increase directly on to the consumer by increasing their alcoholic beverage prices by exactly that amount [22]. The price change $(\Delta P)$ will therefore increase by $\mathrm{Ti}^{*} 0.2, \mathrm{Ti}^{*} 0.5$, and $\mathrm{Ti}^{*} 1$, respectively, where $\mathrm{Ti}$ is the current tax.

After estimating the impact of price increases on consumption, the impact of consumption on cancer was modelled. The relationship between the former parameters is usually called price elasticity (Formula (1); see [23], for a definition). Price elasticity is an economic measure of the change in the quantity demanded or pur- 
Table 1. Percentage of excise duty over the mean price per litre of the finished product for each alcoholic beverage type

\begin{tabular}{|c|c|c|c|c|c|c|}
\hline \multirow[t]{2}{*}{ Country } & \multicolumn{2}{|l|}{ Beer } & \multicolumn{2}{|l|}{ Wine } & \multicolumn{2}{|l|}{ Spirits } \\
\hline & mean price $(€ / L)$ & $\% \operatorname{tax}$ & mean price $(€ / L)$ & $\% \operatorname{tax}$ & mean price $(€ / L)$ & $\% \operatorname{tax}$ \\
\hline Germany & 2.34 & 4.0 & 7.01 & 0 & 16.47 & 31.7 \\
\hline Italy & 3.34 & 10.7 & 10.92 & 0 & 16.85 & 24.6 \\
\hline Kazakhstan $^{\mathrm{a}}$ & 0.93 & 12.2 & 5.19 & 1.4 & 5.84 & 35.0 \\
\hline Sweden & 5.68 & 16.5 & 23.25 & 10.4 & 65.67 & 29.1 \\
\hline
\end{tabular}

${ }^{\text {a }}$ Exchange course: 1 EUR $=500 \mathrm{KZH}($ July 31, 2020).

Table 2. Percentage of preference for each alcoholic beverage type and modelled price elasticity for non-heavy drinkers

\begin{tabular}{|c|c|c|c|c|c|c|}
\hline \multirow[t]{2}{*}{ Country } & \multicolumn{2}{|l|}{ Beer } & \multicolumn{2}{|l|}{ Wine } & \multicolumn{2}{|l|}{ Spirits } \\
\hline & $\%$ preference & elasticity & $\%$ preference & elasticity & $\%$ preference & elasticity \\
\hline Germany & 54.1 & $-0.36(-0.48$ to -0.24$)$ & 27.6 & $-0.60(-0.72$ to -0.48$)$ & 18.4 & $-1.20(-1.4$ to -1.00$)$ \\
\hline Italy & 21.5 & $-0.60(-0.72$ to -0.48$)$ & 68.0 & $-0.36(-0.48$ to -0.24$)$ & 10.5 & $-1.20(-1.44$ to -0.96$)$ \\
\hline Kazakhstan & 37.9 & $-0.60(-0.72$ to -0.48$)$ & 3.6 & $-1.20(-1.44$ to -0.96$)$ & 58.5 & $-0.36(-0.48$ to -0.24$)$ \\
\hline Sweden & 38.2 & $-0.60(-0.72$ to -0.48$)$ & 45.6 & $-0.36(-0.48$ to -0.24$)$ & 16.2 & $-1.20(-1.44$ to -0.96$)$ \\
\hline
\end{tabular}

Values given in parentheses are $95 \%$ confidence intervals.

chased of a product in relation to its price change, which is mathematically described in Formula (1):

$$
E=\Delta Q / \Delta P
$$

where $E$ = elasticity, $Q$ = quantity of a product demanded or purchased; and $P=$ price.

This formula expresses the proportion of consumption change given a price change. Thus, a value of -0.5 in our context indicates that for a proportional increase in price of $10 \%$, consumption will decrease by $5 \%$. We have obtained the values for price elasticity, which tend to vary based on beverage type, from previous metaanalyses $[24,25]$.

Prior meta-analyses have shown that price elasticities tend to be similar [25-27]. As indicated above, however, they appear to differ by beverage type, which seems to be caused by beverage preference (see Table 2). The price elasticities assumed here are -1.2 (95\% CI: $-1.44,-0.96),-0.6$ (95\% CI: $-0.72,-0.48)$, and -0.36 (95\% CI: $-0.48,-0.24$ ) from the least-preferred to the most-preferred beverage type in a country (based on [24, 25]). From economic theory, it is plausible that the most-preferred beverage should be more inelastic than others, that is, it should change to a lesser degree and its values should therefore be closer to zero.

Price elasticity for heavier drinkers - including but not limited to people with alcohol use disorders [28] - have also been shown to be lower [26], in part because their inability to stop drinking is one of the defining characteristics of alcohol use disorders [29]. For heavy drinkers (defined here as men drinking $>60 \mathrm{~g}$ pure alcohol/day and women $>40 \mathrm{~g} /$ day), we applied the same price elasticity to all cases: -0.28 (95\% CI: $-0.37,-0.19$; based on a meta-analysis [26]).

Taxation Increases on Alcohol and Cancer
We have simulated the number of cancers that could have been averted in 2018 via increasing the duties on alcohol. For this reason, we applied the percentage of changes in exposure to 2008, since the lag time between exposure and cancer incidence must be taken into account [30]. Exposure data have been extracted from Manthey et al. [7].

In order to distinguish the heavy drinkers from other drinkers, we have simulated the distribution of level of drinking in each country with the gamma distribution $[31,32]$. In simulating this distribution, we can determine the percentage of alcohol consumed by heavy drinkers (see online suppl. Table A1 for results). Based on the drinking distribution, the distribution of beverage preference, and price elasticities, the decrease in APC following increases in excise duty can be calculated. For non-heavy drinkers, the decrease in consumption can be calculated as shown in Formula (2):

$$
\begin{aligned}
& A P C-A P C * \% B * \% Q b-A P C * \% W * \% Q w-A P C * \% S * \\
& \% Q s=A P C(1-\% B \% Q b-\% W \% Q w-\% S \% Q s)
\end{aligned}
$$

where $\% \mathrm{~B}, \% \mathrm{~W}$, and $\% \mathrm{~S}$ are the percentages of consumption of beer, wine, and spirits, respectively. The $\% \mathrm{Qb}, \% \mathrm{Qw}$, and $\% \mathrm{Qs}$ are the percentages of change in beer, wine, and spirits consumption, respectively. For heavy drinkers, the formula is less complicated, since there are no differences in elasticities by beverage type (see Formula (3):

$$
A P C-A P C * \% Q a=A P C(1-\% Q a)
$$

where $\% \mathrm{Qa}$ is the difference in consumption for all drinks.

The overall results of applying the price elasticities on indicators of consumption can be seen in online supplementary Table A2. 
Table 3. Alcohol-attributable incident cancers in 4 European countries in 2018 (based on [36]) [55]

\begin{tabular}{|c|c|c|c|c|c|c|}
\hline Country & number & $\begin{array}{l}\text { rate per } \\
1,000,000^{\mathrm{a}}\end{array}$ & number & $\begin{array}{l}\text { rate per } \\
1,000,000[53]^{\mathrm{a}}\end{array}$ & number & $\begin{array}{l}\text { rate per } \\
1,000,000^{\mathrm{a}}\end{array}$ \\
\hline Germany & 9,146 & 101.68 & 12,834 & 140.89 & 21,980 & 119.53 \\
\hline Italy & 3,719 & 56.79 & 6,287 & 94.70 & 10,006 & 74.21 \\
\hline Kazakhstan & 637 & 55.35 & 1,019 & 126.87 & 1,655 & 83.37 \\
\hline
\end{tabular}

a Age-standardized rates based on Doll et al. [55].

Fig. 1. Proportion of new cancer cases averted of all alcohol-attributable cases in 2018 (in \%) based on different increases of excise taxation for alcohol

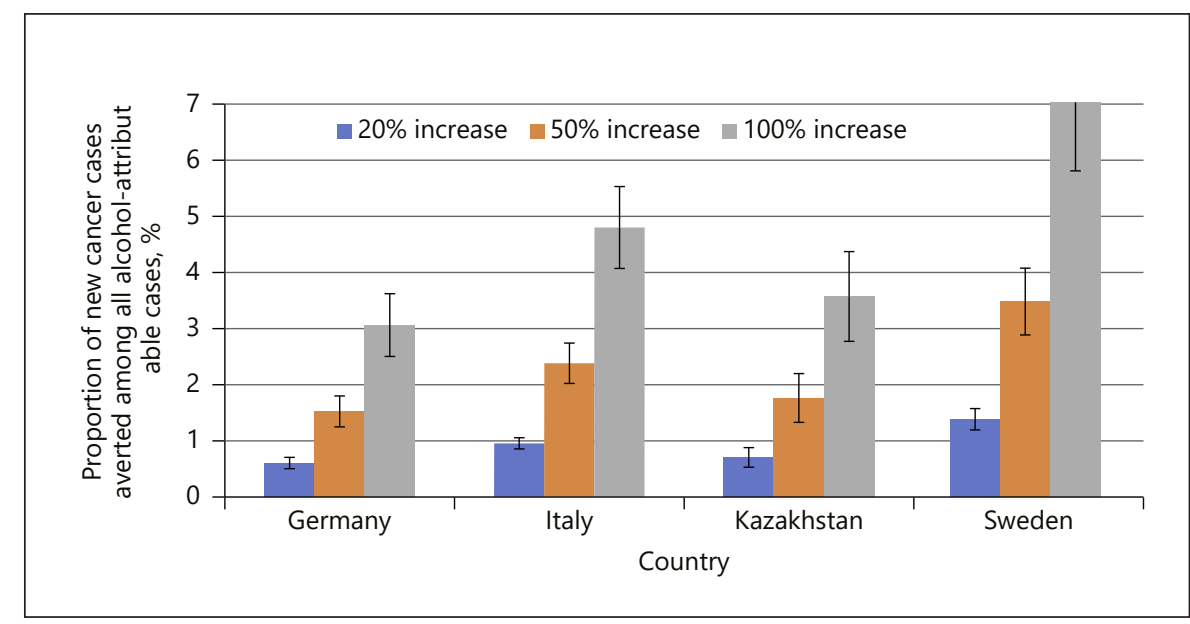

\section{Sensitivity Analyses}

In addition to modelling taxation increases based on the current taxation system, we included an Arcadian normal [33], where we modelled all 4 countries based on the current proportion of excise taxes on price from Finland, representing the highest levels of taxation for the most prevalent beverage in the WHO European Region, beer (for level of taxation, see [19]; for a distribution of beverage types in the WHO European Region, see [15]).

Deriving Alcohol-Attributable Fractions and Applying Them to Cancer Incidence

Based on the reduced alcohol use, we determined alcohol-attributable fractions for each cancer type and compared them to the alcohol-attributable fractions in the baseline scenario. These comparisons were made separately by sex and age for all 4 different scenarios (taxation increases of 20,50, and $100 \%$, assuming the taxation level in Finland), for all cancer types, which are causally related to alcohol. The latter were based on the classification of the International Agency for Research on Cancer, taking only cancer types with sufficient evidence for having a causal impact of alcohol $[5,34]$ :

- Lip and oral cavity cancer (ICD-10 codes: C00-06)

- Oropharyngeal cancers (ICD-10 codes: C09-10)

- Oesophagus cancer (ICD-10 codes: C15)
- Colon and rectum cancers (ICD-10 codes: C18-20)

- Liver cancer (ICD-10 codes: C22)

- Female breast cancer (ICD-10 codes: C50)

- Larynx cancer (ICD-10 codes: C32)

The risk functions used for the calculation of the alcohol-attributable fractions were extracted from the World Cancer Research Fund (WCRF) Continuous Update Project Expert Report [35] and Shield et al. [6], and the data for the total number of incident cancers came from the GLOBOCAN 2018 database in the Global Cancer Observatory [36].

\section{Results}

Alcohol is a major risk factor for cancer in Europe (see above and [37]) and alcohol-attributable cancer cases were estimated at 21,980,10,006, 1,655, and 1,416 for Germany, Italy, Kazakhstan, and Sweden, respectively. Table 3 gives details about the alcohol-attributable incident cancers for the 4 countries in 2018, that is, the cancer cases that would not occur in a world without any alcohol use. As expected, Germany, the country with the highest 
Table 4. Proportion of cancer cases averted in 2018 in each country for different increases in excise duties for alcohol

\begin{tabular}{|c|c|c|c|c|c|c|}
\hline Country & $\begin{array}{l}\% \text { alcohol- } \\
\text { attributable } \\
\text { cancers averted }\end{array}$ & $\begin{array}{l}\% \text { cancers } \\
\text { averted/all } \\
\text { cancers }^{\mathrm{a}}\end{array}$ & $\begin{array}{l}\% \text { alcohol- } \\
\text { attributable } \\
\text { cancers averted }\end{array}$ & $\begin{array}{l}\% \text { cancers } \\
\text { averted/all } \\
\text { cancers }^{\mathrm{a}}\end{array}$ & $\begin{array}{l}\% \text { alcohol- } \\
\text { attributable } \\
\text { cancers averted }\end{array}$ & $\begin{array}{l}\% \text { cancers } \\
\text { averted/all } \\
\text { cancers }^{\mathrm{a}}\end{array}$ \\
\hline Germany & $0.60(0.50-0.72)$ & $0.08(0.07-0.10)$ & $1.52(1.26-1.81)$ & $0.21(0.17-0.25)$ & $3.06(2.55-3.67)$ & $0.42(0.35-0.51)$ \\
\hline Sweden & $1.38(1.18-1.65)$ & $0.12(0.10-0.14)$ & $3.48(2.97-4.16)$ & $0.29(0.25-0.35)$ & $7.03(6.00-8.44)$ & $0.60(0.51-0.71)$ \\
\hline
\end{tabular}

Values given in parentheses are 95\% confidence intervals. ${ }^{a}$ The proportion here denotes the cases averted of all cancers from the following categories: lip and oral cavity, oropharynx, oesophagus, colon and rectum, liver, female breast, and larynx cancers.

Table 5. Cancer cases averted in 2018 if each country had implemented the proportion of excise duties to consumer prices currently used in Finland

\begin{tabular}{lccc}
\hline Country & $\begin{array}{l}\text { Number of } \\
\text { cancers averted }\end{array}$ & $\begin{array}{l}\text { \% Alcohol-attributable } \\
\text { cancers averted }\end{array}$ & $\begin{array}{l}\text { \% Cancers averted/ } \\
\text { all cancers }^{\mathrm{a}}\end{array}$ \\
\hline Germany & $1,616(1,284-1,941)$ & $7.35(5.84-8.83)$ & $1.02(0.81-1.22)$ \\
Italy & $791(697-914)$ & $7.91(6.79-9.13)$ & $0.62(0.53-0.71)$ \\
Kazakhstan & $80(63-99)$ & $4.85(3.81-5.97)$ & $0.72(0.57-0.89)$ \\
Sweden & $92(78-108)$ & $6.49(5.49-7.62)$ & $0.55(0.46-0.64)$ \\
\hline
\end{tabular}

Values given in parentheses are 95\% confidence intervals. ${ }^{\text {a }}$ The proportion here denotes the cases averted of all cancers from the following categories: lip and oral cavity, oropharynx, oesophagus, colon and rectum, liver, female breast, and larynx cancers.

level of alcohol consumption (online suppl. Table A1) had the highest rate of alcohol-attributable cancer for both sexes.

In online supplementary Table A3, the total numbers of incident cancer cases averted for each country are presented after applying the 3 different scenarios of increasing taxation (20,50, and 100\%; see above and online suppl. Appendix for details). In case of a $100 \%$ increase in the alcohol excise taxes, 673, 480, 59, and 100 new cancer cases would be avoided in Germany, Italy, Kazakhstan, and Sweden, respectively. Obviously, the number of incident cancer cases averted depends substantially on the population size of the country, on the prevalence of drinking, and on the level of taxation before the increase. However, in a single country like Germany, if the current very low excise duties were increased, a substantial number of new cancer cases could potentially be averted (673 in case of an increase in excise duties by $100 \%$; see online suppl. Table A3).

However, it is difficult to contextualize and interpret these absolute number of potential cases averted due to different taxation scenarios. For this reason, in Table 4 and Figure 1, we present estimates of the percentages they represent out of all the cancer alcohol-attributable cases (i.e., cancers due to alcohol as presented in Table 3) and of all cancer cases for cancer types whose risk is increased by alcohol consumption.

According to this table, since we did proportional increases, the countries in which a higher percentage of cancer cases due to alcohol could have been averted are those where the current taxation rate is the highest. Out of the 4 countries under study, the first such country is Sweden and the second Italy. Germany is lowest, given its low overall excise taxation level. If we analyse the percentages of cancers averted over all cancers, again Sweden is highest, followed by Kazakhstan.

Table 5 gives the results of the sensitivity analyses and demonstrates what would happen if all 4 countries implemented the same excise taxation for alcoholic beverages as implemented in Finland (for the derivation of the proportions of consumer price for alcoholic beverage, which 
are determined by excise taxes, see online suppl. Appendix): beer, $41.2 \%$; wine, $14.5 \%$; and spirits, $42.6 \%$.

The results show that marked numbers of incident cancers could been averted if the Finnish level of alcoholspecific taxes had been implemented. In Germany, for example, $>1,600$ cancer cases could have been averted in 2018 alone.

\section{Discussion/Conclusion}

We have shown that raising prices of alcoholic beverages via increased taxation can reduce alcohol use and thus potentially avert significant numbers of new cancer cases. For example, in the scenario with highest increase in excise duties modelled, between 3 and 7\% of all alcohol-attributable cancer cases were averted, which translated for Germany, the country with the lowest taxation rates at baseline, into 673 cancer cases averted in 2018 (see online suppl. Table A3). If Germany were to implement the Finnish level of excise taxes, $>1,600$ new cancer cases could have been averted in 2018 . These numbers clearly signal a matter of public health importance, even more so as other alcohol-attributable morbidity and mortality will be averted as well (for an overview of alcohol-attributable mortality, see [6]). Obviously, the absolute number of cancer cases averted will depend mainly on the size of the population, the drinking level, and the distribution of cancers in the respective countries, but the relative sizes in achievable reduction are similar. Before we discuss the results further, we would like to point out the limitations of our approach.

As for all modelling studies, the major limitation lies with the assumptions underlying the model. While we did model the impact of alcohol use on cancer in a dose-dependent manner, separated by sex and age groups, 2 parameters were not available by sex or age: first, we did not have the distribution of beverage types by sex and age, and second, we assumed that elasticities were the same for all groups, defined by sex and age. Modelling these 2 parameters as though they were universal may have introduced some error. Another point is that the main scenarios were modelled as proportional increases based on current levels of excise taxation. This would lead to higher proportions averted for countries with higher levels of excise taxation.

As for elasticities, we only differentiated according to beverage preference and level of consumption. While this seems justified based on the literature - where major reviews and meta-analyses found similar elasticities [24-28,
38 - this also may have introduced some bias. Another potential bias of our modelling was the lack of modelling cross-elasticities between alcoholic beverages or between alcohol and other substances such as cannabis. However, such cross-elasticities often are found to be small [39]. An additional difficulty here is the potential increase in unrecorded consumption [40] as an unintended consequence of taxation increases. While this argument has been frequently made in past discussions, often by the alcohol industry [41], recent experiences in Europe do not seem to indicate a marked increase in unrecorded consumption as a consequence of taxation increases (e.g., in Russia or in Kazakhstan [42, 43]). To avoid such unintended consequences, a stepwise implementation of taxation and cross-border treaties with neighbouring countries - to avoid large differences in the price of alcoholic beverages - might help.

Alcohol use data seem to have relatively few biases in this region, where the majority is based on recorded consumption (maybe with the exception of the level of unrecorded consumption in Kazakhstan, which is part of a region with a traditionally high level of unrecorded consumption [40]). However, considerations of sex- and agespecific estimates relied on survey data and hence might have been influenced by underreporting and other biases [44]. Finally, the dose-response curves between level of alcohol use and cancer risk seem to be relatively stable as well in the different meta-analyses.

Alcohol prices can be raised not only through excise rates but also through other non-alcohol-specific taxes such as value-added taxes or via minimum unit pricing. What is important is the reduction of financial affordability of alcohol at the population level, and this can be achieved through different kinds of taxation schemes (for further discussion, see [23]). Affordability needs to remain low over time, and thus, adjustment for inflation of all taxation relating to alcoholic beverages is needed otherwise, alcohol becomes relatively cheaper over time.

Kazakhstan is an interesting case here, as rates of excise duties and minimum unit prices have, in combination, increased over time, making alcohol steadily less affordable [43]. This strategy has been proven to be effective in reducing mortality, especially mortality of working-age males in Russia and Belarus in the past [42, $45,46]$, and there is evidence to suggest that the same reductions in mortality were achieved in Kazakhstan at least partially through higher alcohol prices [47]. However, this reduction cannot be attributed to pricing interventions alone, as several alcohol control measures were recently introduced in this country [48]. As for value- 
added taxes, while affecting the price, it should be noted that such taxes usually apply to all foods and thus would not recover the economic costs related specifically to alcohol use. As found in all major studies on the economic costs of alcohol use, alcohol-attributable costs not only comprise expenses for the healthcare system but also the costs of the legal system (e.g., drink-driving and alcoholattributable aggression), as well as productivity losses [49, 50]. Based on traditional economic theory (e.g., the concept of Pigouvian tax), all additional costs incurred by alcohol use (i.e., the so-called externalities [27]) should be recovered by the state via specific taxation, and valueadded taxes on all consumer goods do not contribute here. Minimum unit prices are another measure to increase prices at the lower end of the price scale. This intervention has recently been shown to affect heavy drinkers in lower socioeconomic strata especially [51]. As a consequence, adequately set minimum unit prices are important in the alcohol policy mix but not specifically for cancer, as this disease category is mainly related to overall volume of alcohol use and not to irregular heavy drinking occasions, with relatively flat risk-relation curves [52].

The main result of our analyses is, however, that more is possible in the prevention of alcohol-attributable cancers. More than 4 million people are diagnosed with cancer in the WHO European Region each year [36], and thousands of such cancers could be averted, if all countries in this region adopted more stringent systems in excise taxation, or if the EU increased their minimum excise tax levels (which are as low as 0 EUR for wine).

In Germany, for example, the government could not only avoid over 1,600 new cancers per year, it could also increase their tax revenue if they implemented the same level of excise duties as Finland. And Finland is not an Arcadian utopia: it is a member of the EU with similar standards of healthcare and economic power [53]. Implementing Finnish rates for alcohol excise duties would not only decrease the number of new cancer cases, and subsequently cancer mortality, but also reduce many other health burdens related to alcohol $[52,54]$, and thus would contribute to a reduction in all-cause mortality and to an increase in life expectancy.

\section{Acknowledgements}

The authors would like to thank Ms. Astrid Otto for English copy-editing and referencing. We would also like to thank Dr. Jakob Manthey for proofreading the R-programming.

\section{Statement of Ethics}

The research reported here only analysed publicly available secondary data and did not involve human subjects and thus was exempted from research ethics review at the Centre for Addiction and Mental Health. It was conducted ethically in accordance with the World Medical Association Declaration of Helsinki.

\section{Conflict of Interest Statement}

The authors have no conflicts of interest to declare.

\section{Funding Sources}

The authors (J.R. and B.S.) acknowledge funding from the Canadian Institutes of Health Research's Institute of Neurosciences, Mental Health and Addiction (Canadian Research Initiative in Substance Misuse Ontario Node Grant SMN-13950). This article was also supported in part by the EU Health Programme 2014-2020 under a service contract with the Consumers, Health, Agriculture and Food Executive Agency (CHAFEA) acting under a mandate from the European Commission (FAR SEAS - 20187106). Finally, this contribution was enabled by the WHO Collaborating Centre at the Centre for Addiction and Mental Health in Toronto, the Public Health Agency of Catalonia, and the WHO European Region.

\section{Author Contributions}

P.R. helped conceptualize, set up, and estimate the model, and contributed to the first and subsequent drafts. C.K. and M.N. helped conceptualize, gathered information on elasticities, and contributed to all drafts. C.F.-B. helped conceptualize and contributed to the writing. K.D.S. contributed to the modelling and to the writing. B.S. contributed to the economic model and to the writing. J.R. obtained funding, helped conceptualize, and contributed to all drafts and the writing. All authors approved the final version.

\section{Disclaimers}

C.F.-B. is a staff member of the WHO. M.N.. is a WHO consultant. The authors alone are responsible for the views expressed in this publication, and they do not necessarily represent the decisions or the stated policy of the World Health Organization. Also, where authors are identified as personnel of the International Agency for Research on Cancer, the authors alone are responsible for the views expressed in this article, and they do not necessarily represent the decisions, policy, or views of the International Agency for Research on Cancer. The information and views set out in this article in addition do not necessarily reflect the official opinion of the EU Commission/Executive Agency. The Commission/Executive Agency do not guarantee the accuracy of the data included in this study. Neither the Commission/Executive Agency nor any person acting on the Commission's/Executive Agency's behalf may be held responsible for the use that may be made of the information contained therein. 


\section{References}

1 European Commission. Non-communicable diseases: Cancer. 2020. Accessed 2020 Jul 31. Available from: https://ec.europa.eu/health/ non_communicable_diseases/cancer_en.

2 World Health Organization Regional Office for Europe. WHO European Office for the Prevention and Control of NCDs (NCD Office). 2020. Accessed 2020 Jul 31. Available from: https://www.euro.who.int/en/healthtopics/noncommunicable-diseases/pages/ who-european-office-for-the-preventionand-control-of-noncommunicable-diseasesncd-office.

3 World Health Organization Regional Office for Europe. Noncommunicable diseases. Copenhagen: WHO; 2020. Accessed 2020 Jul 31. Available from: https://www.euro.who.int/ en/health-topics/noncommunicable-diseases.

4 European Public Health Alliance. Joint Statement I Prevention at the heart of Europe's Beating Cancer Plan. Brussels: European Public Health Alliance; 2020. Accessed 2020 Aug 4. Available from: https://epha.org/jointstatement-i-prevention-at-the-heart-of-europes-beating-cancer-plan/.

5 International Agency for Research on Cancer. IARC Monographs on the evaluation of carcinogenic risks to humans 100E Personal Habits and Indoor Combustions. Lyon, France: International Agency for Research on Cancer; 2012.

6 Shield K, Manthey J, Rylett M, Probst C, Wettlaufer A, Parry CDH, et al. National, regional, and global burdens of disease from 2000 to 2016 attributable to alcohol use: a comparative risk assessment study. Lancet Public Health. 2020;5(1):e51-61.

7 Manthey J, Shield KD, Rylett M, Hasan OSM, Probst C, Rehm J. Global alcohol exposure between 1990 and 2017 and forecasts until 2030: a modelling study. Lancet. 2019;393(10190): 2493-502.

8 Rehm J, Shield KD, Weiderpass E. Alcohol consumption: a leading risk factor for cancer. In: Wild CP, Weiderpass E, Stewart BW, editors. World cancer report: cancer research for cancer prevention. Lyon, France: International Agency for Research on Cancer; 2020. p. 68-76.

9 Rovira P, Rehm J. Estimation of cancers caused by light to moderate alcohol consumption in the European Union. EJPH. 2020.

10 Soerjomataram I, Shield K, Marant-Micallef C, Vignat J, Hill C, Rogel A, et al. Cancers related to lifestyle and environmental factors in France in 2015. Eur J Cancer. 2018;105:10313.

11 Chisholm D, Moro D, Bertram M, Pretorius C, Gmel G, Shield K, et al. Are the "best buys" for alcohol control still valid? An update on the comparative cost-effectiveness of alcohol control strategies at the global level. J Stud Alcohol Drugs. 2018;79(4):514-22.

12 Chisholm D, Rehm J, Van Ommeren M, Monteiro M. Reducing the global burden of hazardous alcohol use: a comparative costeffectiveness analysis. J Stud Alcohol. 2004; 65(6):782-93

13 World Health Organization. Global status report on alcohol and health 2018. 2018. Accessed 2019 May 20. Available from: https:// www.who.int/substance_abuse/publications/ global_alcohol_report/en/.

14 Poznyak V, Fleischmann A, Rekve D, Rylett M, Rehm J, Gmel G. The World Health Organization's global monitoring system on alcohol and health. Alcohol Res. 2013;35(2):2449.

15 WHO European Region. Status report on alcohol consumption, harm and policy responses in 30 European countries. Copenhagen, Denmark: WHO European Region; 2019.

16 Rabinovich L, Brutscher PB, De Vries H, Tiessen J, Clift J, Reding A. The affordability of alcoholic beverages in the European Union: understanding the link between alcohol affordability, consumption and harms. Cambridge, UK: Rand Europe; 2009.

17 Allamani A, Beccaria F, Voller F. The puzzle of Italian drinking: trends in alcohol consumption, harms and policy: Italy 1990-2010. Nord Stud Alcohol Drugs. 2010;27(5):46578.

18 Pew Research Center Religion and Public Life Project. The future of world religions: population growth projections, 2010-2050. Washington, USA: Pew Research Center; 2015.

19 European Commission Directorate-General Taxation and Customs Union. Excise duty tables. 2020. Accessed 2020 Jul 22. Available from: https://ec.europa.eu/taxation_customs/sites/taxation/files/resources/documents/taxation/excise_duties/alcoholic_beverages/rates/excise_duties-part_i_alcohol_ en.pdf.

20 Statista. Business Data Platform: insights and facts across 170 industries and $150+$ countries. 2020. Accessed $2020 \mathrm{Jul} \mathrm{30.} \mathrm{Available}$ from: https://www.statista.com/.

21 Online.zakon.kz. Kodeks Respubliki Kazahstan ot 25.12.2017 N 120-VI ZRK “O nalogah i drugih objazatel'nyh platezhah v bjudzhet (Nalogovyj kodeks)" [Code of the Republic of Kazakhstan dated December 25, 2017 N 120VI 3PK "On taxes and other obligatory payments to the budget (Tax Code)"]. 2020. Accessed 2020 Jul 31. Available from: https:// online.zakon.kz/document/?doc_id = 36148637\#pos = 11003; -35\&sdoc_params = text\%3D\%25D0\%25A1\%25D0\%25BF\%25D0 \%25B8\%25D1\%2580\%25D1\%2582\%25D0\% 25BE\%25D1\%2581\%25D0\%25BE\%25D0\%2 5B4\%25D0\%25B5\%25D1\%2580\%25D0\%25 B6\%25D0\%25B0\%25D1\%2589\%25D0\%25B 0\%25D1\%258F\%2520\%25D0\%25BF\%25D1 \%2580\%25D0\%25BE\%25D0\%25B4\%25D1\% 2583\%25D0\%25BA\%25D1\%2586\%25D0\%2 5B8\%25D1\%258F\%2520\%25D0\%25BC\%25 D0\%25B5\%25D0\%25B4\%25D0\%25B8\%25D
1\%2586\%25D0\%25B8\%25D0\%25BD\%25D1 \%2581\%25D0\%25BA\%25D0\%25BE\%25D0 \%25B3\%25D0\%25BE\%26mode\%3Dindoc\% 26topic_id\%3D36148637\%26spos\%3D1\%26 tSynonym\%3D1\%26tShort\%3D1\%26tSuffix $\% 3 \mathrm{D} 1 \&$ sdoc_pos $=0$.

22 Nelson JP, Moran JR. Effects of alcohol taxation on prices: a systematic review and metaanalysis of pass-through rates. BE J Econ Anal Policy. 2019;20(1).

23 Sornpaisarn B, Shield KD, Österberg E, Rehm J. Resource tool on alcohol taxation and pricing policies. Geneva, Switzerland: World Health Organization and Others; 2017.

24 Ornstein SI, Levy D. Price and income elasticities of demand for alcoholic beverages. Recent developments in alcoholism, Vol. 1. New York: Plenum; 1983. p. 303-45.

25 Fogarty J. The demand for beer, wine and spirits: a survey of the literature. J Econ Surv. 2010;24(3):428-78.

26 Wagenaar AC, Salois MJ, Komro KA. Effects of beverage alcohol price and tax levels on drinking: a meta-analysis of 1003 estimates from 112 studies. Addiction. 2009;104(2): 179-90.

27 Sornpaisarn B, Shield K, Cohen J, Schwartz R, Rehm J. Elasticity of alcohol consumption, alcohol-related harms, and drinking initiation in low- and middle-income countries: a systematic review and meta-analysis. Int $\mathrm{J} \mathrm{Al}$ cohol Drug R. 2013;2(1):45-58.

28 Rehm J, Marmet S, Anderson P, Gual A, Kraus L, Nutt DJ, et al. Defining substance use disorders: do we really need more than heavy use? Alcohol Alcohol. 2013;48(6):633-40.

29 Carvalho AF, Heilig M, Perez A, Probst C, Rehm J. Alcohol use disorders. Lancet. 2019; 394(10200):781-92.

30 Grundy A, Poirier AE, Khandwala F, McFadden A, Friedenreich CM, Brenner DR. Cancer incidence attributable to alcohol consumption in Alberta in 2012. CMAJ Open. 2016; 4(3):E507.

31 Kehoe T, Gmel G, Shield KD, Gmel G, Rehm J. Determining the best population-level alcohol consumption model and its impact on estimates of alcohol-attributable harms. Popul Health Metr. 2012;10(1):6.

32 Rehm J, Kehoe T, Gmel G, Stinson F, Grant B, Gmel G. Statistical modeling of volume of alcohol exposure for epidemiological studies of population health: the US example. Popul Health Metr. 2010;8(1):3.

33 Collins D, Lapsley H, Brochu S, Easton B, Perez-Gomez A, Rehm J, et al. International guidelines for the estimation of the avoidable costs of substance abuse. Ottawa: Health Canada; 2006.

34 International Agency for Research on Cancer. IARC Monograph 96 on the Evaluation of Carcinogenic Risks to Humans. Alcoholic beverage consumption and ethyl carbamate (urethane). Lyon, France: International Agency for Research on Cancer (IARC); 2010. 
35 World Cancer Research Fund/American Institute for Cancer Research. Diet, Nutrition, Physical Activity and Cancer: a Global Perspective. Continuous Update Project Expert Report 2018. 2018. Accessed 2020 Aug 4. Available from: www.dietandcancerreport. org.

36 Ferlay J, Ervik M, Lam F. Global cancer observatory: cancer today. Lyon, France: International Agency for Research on Cancer; 2018.

37 Rehm J, Shield KD. Alcohol use and cancer in the European Union. A review. European Addiction Research; 2020.

38 Nelson JP. Meta-analysis of alcohol price and income elasticities: with corrections for publication bias. Health Econ Rev. 2013;3(1):17.

39 Meng Y, Brennan A, Purshouse R, Hill-McManus D, Angus C, Holmes J, et al. Estimation of own and cross price elasticities of alcohol demand in the UK: a pseudo-panel approach using the Living Costs and Food Survey 2001-2009. J Health Econ. 2014;34: 96-103.

40 Rehm J, Kailasapillai S, Larsen E, Rehm MX, Samokhvalov AV, Shield KD, et al. A systematic review of the epidemiology of unrecorded alcohol consumption and the chemical composition of unrecorded alcohol. Addiction. 2014;109(6):880-93.

41 International Alliance for Responsible Drinking (IARD). Policy review in brief: taxation of beverage alcohol. 2018. Accessed 2020 Aug 5. Available from: https://www.iard.org/ getattachment/660ef449-ce90--414e-8064-3891487581 c2/iard-policy-review-taxationof-beverage-alcohol.pdf.
42 Nemtsov A, Neufeld M, Rehm J. Are trends in alcohol consumption and cause-specific mortality in Russia between 1990 and 2017 the result of alcohol policy measures? J Stud Alcohol Drugs. 2019;80(5):489-98.

43 Neufeld M, Bobrova A, Davletov K, Štelemékas M, Stoppel R, Ferreira-Borges C, et al. Alcohol control policies in Former Soviet Union countries: a narrative review of three decades of policy changes and their apparent effects. Drug Alcohol Rev. Forthcoming 2020.

44 Kilian C, Manthey J, Probst C, Brunborg GS, Bye EK, Ekholm O, et al. Why is per capita consumption underestimated in alcohol surveys? Results from 39 surveys in 23 European countries. Alcohol Alcohol. 2020 Aug 14; 55(5):554-63.

45 Grigoriev P, Bobrova A. Alcohol control policies and mortality trends in Belarus. Drug Alcohol Rev. Forthcoming 2020.

46 Neufeld M, Ferreira-Borges C, Gil A, Manthey J, Rehm J. Alcohol policy has saved lives in the Russian Federation. Int J Drug Policy. 2020;80:102636.

47 Davletov K, Mereke A, Tussupbekova S, Tolegenova A. P119 The impact of minimal alcohol price policy on premature CVD mortality in Kazakhstan. Eur Heart J. 2020;41(Suppl 1).

48 WHO Regional Office for Europe. Implementing alcohol policies in the Commonwealth of Independent States A workshop of "first-mover" countries. Moscow: WHO Regional Office for Europe and WHO; 2020.
49 Anderson P, Baumberg B. Alcohol in Europe. A Public Health Perspective. 2006. Accessed 2018 Apr 4. Available from: http://www.ias. org.uk/uploads/alcohol_europe.pdf.

50 Rehm J, Mathers C, Popova S, Thavorncharoensap $\mathrm{M}$, Teerawattananon $\mathrm{Y}$, Patra J. Global burden of disease and injury and economic cost attributable to alcohol use and alcohol-use disorders. Lancet. 2009;373(9682): 2223-33.

51 O'Donnell A, Anderson P, Jane-Llopis E, Manthey J, Kaner E, Rehm J. Immediate impact of minimum unit pricing on alcohol purchases in Scotland: controlled interrupted time series analysis for 2015-18. BMJ. 2019; 366:15274.

52 Rehm J, Gmel GE, Gmel G, Hasan OSM, Imtiaz S, Popova $S$, et al. The relationship between different dimensions of alcohol use and the burden of disease: an update. Addiction. 2017;112(6):968-1001

53 The World Bank. GDP, PPP (current international \$). 2020. Accessed 2020 Aug 3. Available from: https://data.worldbank.org/indicator/NY.GDP.MKTP.PP.CD.

54 Global Health Data Exchange (GHDx). GBD Results Tool for the Global Burden of Disease 2017 Study. Seattle, Washington: Institute for Health Metrics and Evaluation; 2020. Accessed 2020 Apr 2. Available from: http:// ghdx.healthdata.org/gbd-results-tool.

55 Doll R, Payne P, Waterhouse J. Cancer incidence in five continents: A technical report. Berlin: Union for International Cancer Control; 1966. 